Bond University

Research Repository

\title{
E⿺辶N)
}

\section{Short- and long-term association of lipid-lowering drug treatment and cardiovascular disease by estimated absolute risk in the Second Australian National Blood Pressure study}

Ho, Chau L.B.; Chowdhury, Enayet K.; Breslin, Monique; Doust, Jenny; Reid, Christopher M.; Wing, Lindon M.H.; Nelson, Mark R.; Beilin, Lawrence J.; Jennings, Garry L.; Johnston, Collin I.; Macdonald, Graham J.; Marley, John E.; McNeil, John J.; Morgan, Trefor O.; Ryan, Philip; West, Malcolm J.

Published in:

Journal of Clinical Lipidology

DOI:

10.1016/j.jacl.2018.08.014

Licence:

CC BY-NC-ND

Link to output in Bond University research repository.

Recommended citation(APA):

Ho, C. L. B., Chowdhury, E. K., Breslin, M., Doust, J., Reid, C. M., Wing, L. M. H., Nelson, M. R., Beilin, L. J., Jennings, G. L., Johnston, C. I., Macdonald, G. J., Marley, J. E., McNeil, J. J., Morgan, T. O., Ryan, P., \& West, M. J. (2019). Short- and long-term association of lipid-lowering drug treatment and cardiovascular disease by estimated absolute risk in the Second Australian National Blood Pressure study. Journal of Clinical Lipidology, 13(1), 148-155. https://doi.org/10.1016/j.jacl.2018.08.014

\section{General rights}

Copyright and moral rights for the publications made accessible in the public portal are retained by the authors and/or other copyright owners and it is a condition of accessing publications that users recognise and abide by the legal requirements associated with these rights.

For more information, or if you believe that this document breaches copyright, please contact the Bond University research repository coordinator. 
Word count for text: 2796

Titles: Short- and long-term association of lipid-lowering drug treatment and cardiovascular disease by estimated absolute risk in the Second Australian National Blood Pressure study (ANBP2)

Running head: LLT for primary prevention of CVD in the elderly

Authors: Chau L.B. Ho ${ }^{1}$, Enayet K. Chowdhury ${ }^{2}$, Monique Breslin ${ }^{1}$, Jenny Doust ${ }^{3}$, Christopher M. Reid ${ }^{2,4}$, Lindon M.H Wing ${ }^{5}$, Mark R. Nelson ${ }^{1,2}$ on behalf of the 2 nd Australian National Blood Pressure Study Management Committee.

Affiliations: ${ }^{1}$ Menzies Institute for Medical Research, University of Tasmania, Hobart, Australia, ${ }^{2} \mathrm{CCRE}$ Therapeutics, School of Public Health and Preventive Medicine, Monash University, Melbourne, Australia, ${ }^{3}$ Faculty of Health Sciences and Medicine, Bond University, Gold Coast, Australia, ${ }^{4}$ School of Public Health, Curtin University, Perth, Australia, ${ }^{5}$ College of Medicine and Public Health, Flinders University, Adelaide, Australia

Corresponding author: Dr. Chau L.B. Ho, Menzies Institute for Medical Research, University of Tasmania, Private Bag 23, Hobart TAS 7001, Australia. Tel: +61406656898. Fax: +61362264734. Email: chau.ho@utas.edu.au. 


\begin{abstract}
Background

There is currently insufficient evidence to support the use of lipid-lowering drug treatment (LLT) for primary prevention of cardiovascular disease (CVD) in the elderly.
\end{abstract}

\title{
Objectives
}

We examined the relationship of early initiation of LLT with short- and long-term allcause and CVD mortality in persons older than 65 years in this post-hoc study from the Second Australian National Blood Pressure study (ANBP2).

\section{Methods}

In- and post-trial observational study. 4257 hypertensive participants aged 65 to 84 years within Australian family practices were randomized to an angiotensin converting enzyme-inhibitor or a diuretic treatment group. After excluding participants with a prior history of CVD, the cohort was stratified into 'LLT' and 'no LLT' subgroups based on LLT status at randomization.

\section{Results}

At randomization the participants had a mean age of 72 years, average blood pressure $(\mathrm{BP})$ of $168 / 91 \mathrm{mmHg}$ and estimated 5-year CVD risk of $18.7 \pm 8.3 \%$. In the overall study population, the association of LLT with long-term (11-years) all-cause and non-CVD mortality was significant [HR 0.78 (95\% Cl 0.66-0.92, p=0.003) and HR $0.70(95 \% \mathrm{Cl} 0.54-0.90, \mathrm{p}=0.006)$ respectively]. Magnitudes of the association of LLT with long-term mortality and the association with short-term mortality were similar, however, no statistically significant association with short-term mortality was observed. In the subgroup analysis by baseline 5-year CVD risk, LLT participants in the highest risk tertile had a substantially lower relative risk for short-term all-cause mortality (HR 0.31, 95\% Cl 0.13-0.71, p for interaction 0.02), compared to those with lower estimated CVD risk. All analyses were adjusted for baseline and in-trial characteristics.

\section{Conclusion}


Our study showed a strong association between LLT and reduced long-term allcause mortality. Thus, our findings support recommendations of the use of LLT in patients over 65, particularly those with high CVD risk who were more likely to obtain additional benefits in the short-term. The findings also suggested that mortality benefits of LLT for the elderly may take longer to become evident.

\section{Highlights}

- Our study supports the use of LLT for primary prevention of CVD in the elderly.

- LLT was associated with a reduced long-term all-cause mortality.

- High risk participants obtained further benefits for short-term all-cause mortality.

Key Words: lipid-lowering drug treatment, cardiovascular disease, primary prevention, absolute cardiovascular risk, elderly. 


\section{Background}

The global population is ageing. In 2015 there were 617 million (8.5\%) people aged over 65 years and this is likely to reach 1.6 billion (17\%) by $2050{ }^{1}$. Cardiovascular disease (CVD) remains the leading burden of disease in this age group, being $30 \%$ of the total ${ }^{2}$. Lipid-lowering drug treatment (LLT), particularly statins, plays a key role in the prevention of CVD ${ }^{3-5}$. More than $40 \%$ of the Australian and US populations aged 75 and over are currently taking $\operatorname{LLT}{ }^{6,7}$ and this number is projected to grow as most of the LLTs come off patent and are therefore available at lower cost.

Most of the evidence for benefits from the use of LLT in those 65 years or over are from trials of secondary prevention of CVD or in mixed populations of those with and without a previous history of CVD ${ }^{8-16}$ whereas insufficient evidence is available to support the use of LLT for primary prevention in the elderly ${ }^{17-20}$. A systematic review and meta-analysis by Savarese et al ${ }^{21}$ related predominantly to primary prevention reported no significant mortality benefit of statin treatment in individuals aged 65 and over, although there were significant reductions in myocardial infarction (MI) and stroke. The average follow-up in the studies in this analysis was 3.5 years (range: $1.0-5.2$ years) ${ }^{9,13-16,22}$.

A prospective cohort study with 7.3 years follow-up ${ }^{23}$ found substantial effects of early statin use (on-treatment versus no treatment at baseline) on major CVD events and all-cause mortality in the elderly ( $\geq 65$ years) without CVD at baseline. This result stands despite a possible dilution of effects due to $13 \%$ of non-drug users at baseline initiating treatment during the study. In contrast, another elderly cohort 24 with median follow-up at 9.1 years found no benefits for CVD or CHD events except stroke. Evidence for both short- and long-term benefits of LLT in older adults thus remains inconsistent. From patients' perspectives, other considerations in this age group impacting on chronic drug therapy are drug adherence, the possibility of adverse drug effects and the potential for consideration of medication discontinuation when other issues such as frailty and life expectancy become dominant ${ }^{25,26}$. In this current post-hoc study in a cohort of hypertensive elderly from the Second Australian National Blood Pressure study (ANBP2) ${ }^{27}$, we have examined the relationship 
between the use of LLT at randomization and short- (4 year) and long-term (11 year) all-cause and CVD mortality in those aged 65 years or over.

\section{Materials and methods}

We conducted a post-hoc analysis relating to a cohort from the Second Australian National Blood Pressure study (ANBP2) ${ }^{27}$. ANBP2 had an open-labelled design with blinded end-point assessment. Participants aged 65-84 years at enrolment were randomized into an angiotensin-converting enzyme treatment group (enalapril recommended) or a thiazide diuretic treatment group (hydrochlorothiazide recommended) within Australian family practices. At entry, eligible participants had an average randomized blood pressure (BP) of 160/90 mmHg or over. Short-term mortality outcomes were followed for a median 4.1 years (from 1995 to 2001) as described by Wing et al ${ }^{27}$. A blinded independent endpoint committee adjudicated all study endpoints. An extended observation relating to survival status was conducted to a median 10.8 years (4.1-years in-trial and 6.7 years post-trial) using linkage to the Australian National Death Index as described by Nelson et al ${ }^{28}$ to investigate longer term all-cause or CVD mortality. In this study, fatal cardiovascular events were comprised of sudden cardiac deaths, fatal stroke, fatal myocardial infarction, and 'other' cardiovascular causes of death.

To focus on primary prevention we excluded participants who had had previous CVD events at baseline $(n=705)$ and those who were initiated on LLT $(n=1292)$ during the clinical trial period because we were uncertain whether they were prescribed LLT due to a CVD occurrence or an increased cholesterol level. Participants were re-stratified by LLT status at entry. Subsequently, we compared the outcomes between those who were on LLT (LLT group) and those who were not (no LLT) at randomization (baseline) regardless of their randomized treatment.

\section{Subgroup by CVD risk}

To investigate how the effect of LLT was affected by baseline CVD risk, we performed a subgroup analysis stratified by tertile of 5-year predicted CVD risk score at entry. The risk score was calculated by the Framingham absolute risk equation as used in the Australian National Vascular Disease Prevention Alliance (NVDPA) guideline ${ }^{29}$. As per the guideline, participants were automatically scored at high risk $(>15 \%)$ if they had systolic $\mathrm{BP} \geq 180 \mathrm{mmHg}$ and/or diastolic $\mathrm{BP} \geq 110 \mathrm{mmHg}$, total 
cholesterol $>7.5 \mathrm{mmol} / \mathrm{l}$, diabetes and/or estimated glomerular filtration rate $<45$ $\mathrm{ml} / \mathrm{min} / 1.73 \mathrm{~m}^{2}$. For participants over 75 years of age, the age value was set at 74 in the risk calculation.

\section{Statistical analysis}

The differences between the 'LLT' and 'no LLT' groups for baseline characteristics were tested by t-tests for continuous variables and Chi-square tests for categorical variables. Cox proportional hazard models were used to estimate the hazard ratios (HRs) and corresponding 95\% confidence interval (Cls) for outcomes for participants in the 'LLT' group compared with those in 'no LLT' group. Participants were followed-up from entry to the time of event (deaths) or loss of vital status or the end of the follow-up (maximum 6 years for the short-term analysis and 14 years for the long-term analysis). Those who did not have an event throughout the observed time scale were considered as censored on 30 Sep 2001 for the short-term and 31 Oct 2009 for the long-term follow-up phase. The proportional assumption was checked by a test for interaction of LLT group with time. All of the analyses were adjusted for baseline characteristics (age, sex, family history of CVD, non-HDL cholesterol, diabetes, anti-platelet use), in-trial characteristics (number of assigned in-trial BP lowering drugs), and clustered on the general practice clinic from which participants originated. Further adjustment models were tested in sensitivity analysis. In addition, we conducted subgroup analyses stratified by age, sex and diabetes at baseline to investigate the impacts of these factors on the association of LLT and mortality outcomes. The Cox regression models were used to test for interaction of treatment in the subgroup analyses. The significance of treatment effect was set to 0.05. Data management for all analyses was performed by using Stata version 12 for Windows.

\section{Results}

\section{Patient characteristics}

Our study included 4257 out of the original ANBP2 cohort of 6083 participants, approximately $70 \%$ of the total ANBP2 cohort. As shown in table 1, at study entry, participants had a mean age of 72 years, mean BP of $168 / 91 \mathrm{mmHg}$, mean plasma total cholesterol of $5.5 \pm 0.9 \mathrm{mmol} / \mathrm{l}$ and $\mathrm{HDL}$ cholesterol of $1.4 \pm 0.5 \mathrm{mmol} / \mathrm{l}$. Compared with the 'no LLT' group, more female and younger participants were on 
LLT at baseline. Also, LLT participants were more likely to have a family history of CVD, diagnosed diabetes mellitus, and be on antiplatelet and previous BP lowering drug treatment. Although these participants were on LLT, they still had higher average plasma total cholesterol level and non-HDL cholesterol. This may be attributable either to insufficient adherence to LLT or to the non-specific treatment target recommended at the time (1995-2001) for primary prevention. In general, based on the estimated risk over 5-year, all participants were at high risk of CVD mean risk: $18.7 \% \pm 8.3 \%$ using the Anderson equation ${ }^{30}$ as per the Australian NVDPA guideline ${ }^{29}$. The estimated CVD risk score of the no LLT group $(18.9 \% \pm$ 8.3\%) was slightly higher than the LLT group, suggesting that LLT was prescribed based on the participant's cholesterol level, not on absolute CVD risk.

Table 1. Baseline characteristics by lipid-lowering drug treatment.

\begin{tabular}{|c|c|c|c|c|}
\hline & $\begin{array}{c}\text { Total } \\
(\mathrm{N}=4257)\end{array}$ & $\begin{array}{l}\text { No LLT } \\
(n=3609)\end{array}$ & $\begin{array}{c}\text { LLT } \\
(n=648)\end{array}$ & $\begin{array}{c}p- \\
\text { value }\end{array}$ \\
\hline Age (mean \pm SD in years) & $72.0 \pm 5.0$ & $72.1 \pm 5.0$ & $71.0 \pm 4.4$ & $<0.001$ \\
\hline Female sex n (\%) & $2195(51.6)$ & $1789(49.6)$ & $406(62.7)$ & $<0.001$ \\
\hline Current smoker n (\%) & $305(7.2)$ & $260(7.2)$ & $45(6.9)$ & 0.81 \\
\hline $\begin{array}{l}\text { Systolic } \mathrm{BP} \text { at randomization } \\
\text { (mean } \pm \mathrm{SD}, \mathrm{mmHg} \text { ) }\end{array}$ & $167.6 \pm 12.6$ & $167.7 \pm 12.6$ & $167.4 \pm 12.3$ & 0.58 \\
\hline $\begin{array}{l}\text { Diastolic BP at randomization } \\
\text { (mean } \pm \mathrm{SD}, \mathrm{mmHg} \text { ) }\end{array}$ & $90.8 \pm 8.1$ & $90.8 \pm 8.1$ & $90.8 \pm 7.9$ & 0.89 \\
\hline $\begin{array}{l}\text { Total cholesterol } \\
\text { (mean } \pm \mathrm{SD}, \mathrm{mmol} / \mathrm{l})\end{array}$ & $5.5 \pm 0.9$ & $5.5 \pm 0.9$ & $5.8 \pm 1.1$ & $<0.001$ \\
\hline $\begin{array}{l}\text { HDL cholesterol } \\
\text { (mean } \pm \mathrm{SD}, \mathrm{mmol} / \mathrm{l})\end{array}$ & $1.4 \pm 0.5$ & $1.4 \pm 0.5$ & $1.4 \pm 0.5$ & 0.48 \\
\hline $\begin{array}{l}\text { Non-HDL cholesterol } \\
\text { (mean } \pm \mathrm{SD}, \mathrm{mmol} / \mathrm{l})\end{array}$ & $4.2 \pm 1.0$ & $4.1 \pm 0.9$ & $4.4 \pm 1.1$ & $<0.001$ \\
\hline BMI (mean $\pm \mathrm{SD}, \mathrm{kg} / \mathrm{m} 2)$ & $27.0 \pm 4.2$ & $27.0 \pm 4.2$ & $27.2 \pm 4.1$ & 0.18 \\
\hline $\begin{array}{l}\text { 5-year Framingham risk score } \\
\text { (mean } \pm \mathrm{SD}, \% \text { ) }\end{array}$ & $18.7 \pm 8.3$ & $18.9 \pm 8.3$ & $17.8 \pm 8.1$ & $<0.001$ \\
\hline Diabetes mellitus $\mathrm{n}(\%)$ & $275(6.5)$ & $217(6.0)$ & $58(9.0)$ & 0.01 \\
\hline $\begin{array}{l}\text { Waist circumference } \\
\text { (mean } \pm \mathrm{SD}, \mathrm{cm})\end{array}$ & $94.4 \pm 12.1$ & $94.6 \pm 12.2$ & $93.6 \pm 11.8$ & 0.07 \\
\hline W-H ratio & $0.90 \pm 0.08$ & $0.90 \pm 0.08$ & $0.89 \pm 0.08$ & 0.004 \\
\hline
\end{tabular}




\begin{tabular}{|c|c|c|c|c|}
\hline Current alcohol consumption n (\%) & $3126(73.4)$ & $2660(73.7)$ & $466(71.9)$ & 0.34 \\
\hline Physically active $n(\%)$ & $3332(78.3)$ & $2815(78.0)$ & $517(79.8)$ & 0.31 \\
\hline \multicolumn{4}{|l|}{ Education n (\%) } & \multirow[t]{4}{*}{0.57} \\
\hline Primary school & $997(23.4)$ & $854(23.7)$ & $143(22.1)$ & \\
\hline High school not completed & $1853(43.5)$ & $1560(43.2)$ & $293(45.2)$ & \\
\hline Competed high school or higher & $1407(33.1)$ & $1195(33.1)$ & $212(32.7)$ & \\
\hline \multicolumn{4}{|l|}{ Socio-economic status $\mathrm{n}(\%)$} & \multirow[t]{5}{*}{0.66} \\
\hline 1st quartile (most advantaged) & $1085(25.5)$ & $915(25.4)$ & $170(26.2)$ & \\
\hline 2nd quartile & $1151(27.0)$ & 969 (26.9) & $182(28.1)$ & \\
\hline 3rd quartile & $1365(32.1)$ & $1171(32.5)$ & $194(29.9)$ & \\
\hline 4th quartile (most disadvantage) & $656(15.4)$ & $554(15.4)$ & $102(15.7)$ & \\
\hline \multicolumn{4}{|l|}{ Family history of CVD n (\%) } & \multirow[t]{3}{*}{$<0.001$} \\
\hline Yes & $1986(46.7)$ & $1604(44.4)$ & $382(59.0)$ & \\
\hline Unknown & $496(11.7)$ & $423(11.7)$ & $73(11.3)$ & \\
\hline \multicolumn{5}{|l|}{ Random blood glucose } \\
\hline$($ mean $\pm \mathrm{SD}, \mathrm{mmol} / \mathrm{l})$ & $5.5 \pm 1.8$ & $5.5 \pm 1.8$ & $5.6 \pm 1.9$ & 0.33 \\
\hline \multicolumn{5}{|l|}{ Serum creatinine } \\
\hline$($ mean $\pm S D, \mu \mathrm{mol} / \mathrm{l})$ & $90.8 \pm 19.2$ & $90.8 \pm 19.2$ & $90.8 \pm 18.9$ & 0.96 \\
\hline Antiplatelet use n (\%) & $433(10.2)$ & $341(9.5)$ & $92(14.2)$ & $<0.001$ \\
\hline \multicolumn{5}{|l|}{ Previous BP lowering treatment } \\
\hline n (\%) & $2556(60.0)$ & 2077 (57.6) & $479(73.9)$ & $<0.001$ \\
\hline
\end{tabular}

LLT: lipid-lowering drug treatment, BP: blood pressure, HDL: high-density lipoprotein, BMI: body mass index, $\mathrm{W}-\mathrm{H}$ ratio: waist-hip ratio, CVD: cardiovascular disease. Bold $\mathrm{p}<0.05$

For in-trial characteristics (Table 2), there was no significant difference between the number of 'LLT' and 'no LLT' participants randomized to either ACE-I or diuretic-based therapy. However, LLT participants were more likely to receive a higher number of randomized drugs and had a lower average on-treatment diastolic BP.

Table 2. In-trial characteristics by LLT stratification.

\begin{tabular}{lcccc}
\hline & $\begin{array}{c}\text { Total } \\
(\mathrm{N}=4257)\end{array}$ & $\begin{array}{c}\text { No LLT } \\
(\mathrm{n}=3609)\end{array}$ & $\begin{array}{c}\text { LLT } \\
(\mathrm{n}=648)\end{array}$ & $\begin{array}{c}\mathrm{p}- \\
\text { value }\end{array}$ \\
\hline Randomized to ACE-I n (\%) & $2117(49.7)$ & $1782(49.4)$ & $355(51.7)$ & 0.28
\end{tabular}


BP lowering-drug compliance n (\%) $\quad 1828(67.2) \quad 1532(67.3) \quad 296(66.2) \quad 0.64$

Average on-treatment systolic BP

(mean $\pm \mathrm{SD}, \mathrm{mmHg}$ )

$145.6 \pm 9.9 \quad 145.6 \pm 9.9 \quad 145.4 \pm 9.6$

Average on-treatment diastolic BP

(mean $\pm \mathrm{SD}, \mathrm{mmHg}$ )

$80.8 \pm 5.5$

$80.8 \pm 5.5$

$80.3 \pm 5.2$

0.02

Number of assigned in-trial BP lowering drugs $n(\%)$ $<0.001$

0

1

2

$\geq 3$
195 (4.6)

$2183(51.6)$

1640 (38.7)

$216(5.1)$
175 (4.9)

1902 (53.0)

20 (3.1)

281 (43.4)

1336 (37.3) 304 (46.7)

174 (4.9)
$42(6.5)$

LLT: lipid-lowering drug treatment, ACE-I: Angiotensin Converting Enzyme-Inhibitor, BP: blood pressure. Bold $p<0.05$

Association of LLT and mortality in the total cohort

263 deaths (106 CVD deaths including 13 fatal myocardial infarction, 28 fatal stroke and 65 other CVD deaths) occurred during the in-trial period (median 4.1 years/'short-term'). These numbers increased to an overall 1250 deaths (622 CVD deaths including 124 fatal myocardial infarction, 122 fatal stroke and 376 other CVD deaths) by the end of the extended phase (median 10.8 years/'long-term').

Accumulative incidences of events according to LLT were presented in KM curves in figure 1 of the supplementary material.

In the long-term (10.8 years), LLT participants had a significantly lower adjusted risk of all-cause mortality HR 0.78 (95\% Cl 0.66-0.92, p=0.003). Noticeably, most of the survival benefits were attributable to the effects on long-term non-CVD deaths HR $0.70(95 \% \mathrm{Cl} 0.54-0.90, p=0.006)$, particularly cancer deaths HR 0.62 (95\% Cl 0.44-0.88, p=0.007) (Table 3). Also, magnitudes of the association of LLT with long-term mortality and the association with short-term mortality were similar, however, no statistically significant association on short-term mortality was observed (Table 3 and 4). In terms of CVD mortality, there was no significant difference between the LLT and no LLT groups in either the short (HR 0.86, 95\% $\mathrm{Cl} 0.46-1.61)$ or long term (HR 0.87, 95\% Cl 0.68-1.11).

Table 3. Association between LLT and long-term mortality in tertiles by estimated 5-year CVD risk and in the total cohort. 


\begin{tabular}{|c|c|c|c|c|c|}
\hline \multirow{3}{*}{$\begin{array}{l}\text { Tertiles by estimated } \\
\text { 5-year CVD risk }\end{array}$} & $\begin{array}{l}\text { Number of } \\
\text { event } \%(n)\end{array}$ & $\begin{array}{r}\text { Evel } \\
\text { per } \\
\text { persc }\end{array}$ & $\begin{array}{l}\text { (rate } \\
000 \\
\text { I-year) }\end{array}$ & Univariate & Adjusted * \\
\hline & \multicolumn{4}{|c|}{ No } & \\
\hline & & LLT & LLT & HR (95\%Cl) & HR (95\%Cl) \\
\hline \multicolumn{6}{|l|}{ All-cause mortality } \\
\hline $1^{\text {st }}$ tertile $(2-14.5 \%)$ & $7.0(297)$ & 11.5 & 22.5 & $0.51(0.35-0.74)$ & $0.64(0.44-0.94)$ \\
\hline $2^{\text {nd }}$ tertile $(14.5-22.6 \%)$ & $9.3(398)$ & 21.7 & 29.6 & $0.72(0.53-0.98)$ & $0.85(0.62-1.16)$ \\
\hline $3^{\text {rd }}$ tertile $(22.6-59.8 \%)$ & $13.1(557)$ & 30.7 & 43.3 & $0.70(0.53-0.91)$ & $0.85(0.65-1.11)$ \\
\hline Total & $29.4(1252)$ & 20.6 & 31.6 & $0.64(0.54-0.76)$ & $0.78(0.66-0.92)$ \\
\hline$p$ for interaction & - & - & - & 0.29 & 0.29 \\
\hline \multicolumn{6}{|l|}{ CVD mortality } \\
\hline $1^{\text {st }}$ tertile $(2-14.5 \%)$ & $3.3(141)$ & 5.9 & 10.5 & $0.56(0.33-0.95)$ & $0.74(0.43-1.26)$ \\
\hline $2^{\text {nd }}$ tertile $(14.5-22.6 \%)$ & $4.6(196)$ & 10.9 & 14.5 & $0.74(0.48-1.14)$ & $0.86(0.53-1.38)$ \\
\hline $3^{\text {rd }}$ tertile $(22.6-59.8 \%)$ & $6.6(282)$ & 17.9 & 21.4 & $0.82(0.58-1.16)$ & $0.98(0.69-1.38)$ \\
\hline Total & $14.5(619)$ & 11.1 & 15.4 & $0.71(0.56-0.91)$ & $0.87(0.68-1.11)$ \\
\hline$p$ for interaction & - & - & - & 0.5 & 0.46 \\
\hline \multicolumn{6}{|l|}{ Cancer death } \\
\hline $1^{\text {st }}$ tertile $(2-14.5 \%)$ & $2.0(87)$ & 2.4 & 6.8 & $0.35(0.15-0.80)$ & $0.40(0.17-0.93)$ \\
\hline $2^{\text {nd }}$ tertile $(14.5-22.6 \%)$ & $2.9(125)$ & 7.1 & 9.3 & $0.76(0.44-1.29)$ & $0.86(0.50-1.47)$ \\
\hline $3^{\text {rd }}$ tertile (22.6-59.8\%) & 3.7 (157) & 6.9 & 12.5 & $0.55(0.32-0.95)$ & $0.62(0.35-1.08)$ \\
\hline Total & 8.7 (369) & 5.3 & 9.5 & $0.55(0.39-0.78)$ & $0.62(0.44-0.88)$ \\
\hline$p$ for interaction & - & - & - & 0.27 & 0.28 \\
\hline \multicolumn{6}{|l|}{ Non-CVD death } \\
\hline $1^{\text {st }}$ tertile $(2-14.5 \%)$ & $3.7(156)$ & 5.5 & 11.9 & $0.46(0.27-0.80)$ & $0.57(0.33-0.98)$ \\
\hline $2^{\text {nd }}$ tertile $(14.5-22.6 \%)$ & $4.7(202)$ & 10.9 & 15.1 & $0.71(0.46-1.09)$ & $0.84(0.55-1.30)$ \\
\hline $3^{\text {rd }}$ tertile $(22.6-59.8 \%)$ & $6.5(275)$ & 12.9 & 21.8 & $0.58(0.39-0.87)$ & $0.72(0.48-1.08)$ \\
\hline Total & $14.9(633)$ & 9.5 & 16.2 & $0.57(0.44-0.74)$ & $0.70(0.54-0.90)$ \\
\hline$p$ for interaction & - & - & - & 0.47 & 0.48 \\
\hline
\end{tabular}

LLT: lipid-lowering treatment, CVD: cardiovascular disease. * Age, sex, family history of CVD, non-HDL-C, diabetes, anti-platelet use, clustering effect by general practice, number of assigned in-trial BP lowering drugs. Bold $\mathrm{p}<0.05$.

Table 4. Association between LLT and short-term mortality in tertiles by estimated 5-year CVD risk and in the total cohort. 


\begin{tabular}{|c|c|c|c|c|c|}
\hline \multirow[b]{2}{*}{$\begin{array}{l}\text { Tertiles by estimated } \\
\text { 5-year CVD risk }\end{array}$} & \multirow[t]{2}{*}{$\begin{array}{c}\text { Number } \\
\text { of event } \\
\%(n)\end{array}$} & \multicolumn{2}{|c|}{$\begin{array}{c}\text { Event (rate per } \\
1000 \text { person- } \\
\text { year) }\end{array}$} & \multirow[t]{2}{*}{ Univariate } & Adjusted * \\
\hline & & LLT & No LLT & & HR (95\%Cl) \\
\hline \multicolumn{6}{|l|}{ All-cause mortality } \\
\hline $1^{\text {st }}$ tertile $(2-14.5 \%)$ & $1.2(52)$ & 7.0 & 9.3 & $0.76(0.34-1.67)$ & $0.92(0.41-2.07)$ \\
\hline $2^{\text {nd }}$ tertile $(14.5-22.6 \%)$ & $1.8(76)$ & 14.7 & 12.5 & $1.17(0.64-2.12)$ & $1.39(0.74-2.60)$ \\
\hline $3^{\text {rd }}$ tertile (22.6-59.8\%) & $3.1(134)$ & 6.9 & 24.9 & $0.28(0.12-0.64)$ & $0.32(0.14-0.75)$ \\
\hline Total & $6.2(262)$ & 9.4 & 15.7 & $0.60(0.40-0.90)$ & $0.71(0.47-1.07)$ \\
\hline$p$ for interaction & - & - & - & 0.01 & 0.02 \\
\hline \multicolumn{6}{|l|}{ CVD mortality } \\
\hline $1^{\text {st }}$ tertile $(2-14.5 \%)$ & $0.4(15)$ & 2.0 & 2.8 & $0.70(0.16-3.08)$ & $1.12(0.23-5.39)$ \\
\hline $2^{\text {nd }}$ tertile $(14.5-22.6 \%)$ & $0.8(32)$ & 7.9 & 5.1 & $1.54(0.67-3.56)$ & $1.78(0.71-4.47)$ \\
\hline $3^{\text {rd }}$ tertile $(22.6-59.8 \%)$ & $1.3(57)$ & 3.5 & 10.4 & $0.33(0.10-1.07)$ & $0.35(0.11-1.14)$ \\
\hline Total & $2.4(104)$ & 4.3 & 6.2 & $0.71(0.39-1.29)$ & $0.86(0.46-1.61)$ \\
\hline$p$ for interaction & - & - & - & 0.09 & 0.1 \\
\hline \multicolumn{6}{|l|}{ Cancer death } \\
\hline $1^{\text {st }}$ tertile $(2-14.5 \%)$ & $0.5(23)$ & 3.0 & 4.0 & $0.74(0.22-2.49)$ & $0.77(0.23-2.55)$ \\
\hline $2^{\text {nd }}$ tertile $(14.5-22.6 \%)$ & $0.8(35)$ & 5.6 & 5.9 & $0.96(0.37-2.48)$ & $1.14(0.44-3.00)$ \\
\hline $3^{\text {rd }}$ tertile $(22.6-59.8 \%)$ & $1.1(48)$ & 2.3 & 8.9 & $0.26(0.06-1.08)$ & $0.27(0.06-1.18)$ \\
\hline Total & $2.5(106)$ & 3.6 & 6.3 & $0.58(0.30-1.11)$ & $0.60(0.31-1.17)$ \\
\hline$p$ for interaction & - & - & - & 0.26 & 0.28 \\
\hline \multicolumn{6}{|l|}{ Non-CVD death } \\
\hline $1^{\text {st }}$ tertile $(2-14.5 \%)$ & $0.9(37)$ & 5.0 & 6.4 & $0.78(0.30-2.00)$ & $0.85(0.33-2.18)$ \\
\hline $2^{\text {nd }}$ tertile $(14.5-22.6 \%)$ & $44(1.0)$ & 6.8 & 7.4 & $0.91(0.39-2.16)$ & $1.12(0.46-2.73)$ \\
\hline $3^{\text {rd }}$ tertile (22.6-59.8\%) & $1.8(77)$ & 3.5 & 14.5 & $0.24(0.08-0.77)$ & $0.29(0.09-0.96)$ \\
\hline Total & $3.7(158)$ & 5.1 & 9.5 & $0.53(0.31-0.93)$ & $0.61(0.35-1.06)$ \\
\hline$p$ for interaction & - & - & - & 0.13 & 0.17 \\
\hline
\end{tabular}

LLT: lipid-lowering treatment, CVD: cardiovascular disease. * Age, sex, family history of CVD, non-HDL-C, diabetes, anti-platelet use, clustering effect by general practice, number of assigned in-trial BP lowering drugs. Bold $p<0.05$.

Association of LLT and mortality in a subgroup by 5-year estimated CVD risk

In the subgroup analysis by estimated absolute CVD risk at baseline (Tables 3 and 4), heterogeneity was found for short-term all-cause mortality, but no other 
outcomes. In the highest risk tertile, LLT group had a reduced risk of short-term allcause mortality ( $\mathrm{HR} 0.32,95 \% \mathrm{Cl} 0.14-0.75)$ with $\mathrm{p}$ for interaction of 0.02 , compared to the low and moderate risk tertiles. There was no effect seen in other outcomes in the short or long-term.

\section{Sensitivity analysis}

In subgroup analyses stratified by age, sex and diabetes status at baseline (Table 1 and 2 in Supplementary), regarding long-term and short-term associations between LLT and mortality outcomes, the associations were not statistically different among stratified subgroups. In a further adjusted model, we added characteristics that were statistically different (W-H ratio and previous BP lowering treatment) between the LLT group, systolic BP and diastolic BP at randomization in the adjusted model. The results were similar to the adjusted model, and no substantial difference was recorded.

\section{Discussion}

In this post-hoc analysis of ANBP2, we found a positive association between LLT with long-term all-cause, non-CVD and cancer mortality, but the protective association with CVD mortality did not reach statistical significance. For short-term outcomes, no significant association was recorded, although the magnitudes of the associations (HRs) were similar to the long-term effects.

Our long-term findings are consistent with the long-term ASCOT-LLA trial ${ }^{31}$ and a 7.3-year observational study ${ }^{23}$. All three studies found a significant reduction in all-cause mortality and a non-significant reduction in CVD mortality. Surprisingly, similar to our study, ASCOT-LLA also observed a significant benefit on long-term non-CVD deaths (HR 0.85, 95\%Cl 0.73-0.99). Our study recorded a substantial benefit of LLT on cancer deaths, whereas ASCOT-LLA reported a non-significant effect on cancer deaths (HR 0.92, 95\% $\mathrm{Cl} 0.76-1.12$ ), but a significant effect on deaths related to infectious or respiratory diseases (HR 0.64, 95\% $\mathrm{Cl} 0.42-0.97$ ). The ANBP2 study did not record these outcomes, so we were unable to include these in this analysis. A limitation of our findings is that cancer deaths in both the short- and long-term may be confounded by the status of diagnosed cancer at entry. If the prevalence of diagnosed cancer at study entry were equally distributed between LLT and no LLT group, our results would support findings from previous studies showing 
a substantial reduction of cancer-related deaths by statin treatment in participants either with pre-existing cancer or no cancer ${ }^{32,33}$. In contrast, two meta-analyses ${ }^{5,34}$ of large randomised controlled trials showed no beneficial effect of statins on cancerrelated deaths. Yet, most of these RCTs had a high proportion of participants with previous CVD.

In terms of the short-term outcomes, our findings on all-cause and CVD mortality are consistent with a previous meta-analysis by Savarese ${ }^{21}$ who reported a non-significant effect of LLT on all-cause mortality with an RR 0.94 (95\% Cl 0.861.04; $p=0.21)$ and on CVD mortality with an RR 0.91 (95\% Cl 0.69-1.20; $p=0.49$ ) with a mean follow-up of 3.5 years (range: 1 to 5.2 years). However, in our study, the protective association for all-cause mortality reached statistical significance in the long-term analysis with the median follow-up time of 10.8 years, suggesting that differences in mortality may take longer to accrue.

In the subgroup analysis by CVD risk, LLT showed a greater effect on shortterm all-cause mortality in the highest risk tertile, compared to other lower risk groups. We did not find any significant difference in the low or moderate risk groups regarding other trial endpoints. In contrast to our results, the Cholesterol Treatment Trialists (CTT)' Collaborators ${ }^{5}$ observed a substantial reduction of all-cause mortality on the total cohort $0.91(95 \% \mathrm{Cl} 0.85-0.97)$ but a non-statistically significant heterogeneity ( $p$ for trend=0.2) among risk subgroups (5-year risk at baseline $<5 \%$, $\geq 5 \%$ and $<10 \%, \geq 10 \%$ and $<20 \%, \geq 20 \%$ and $<30 \%, \geq 30 \%$ ). The CTT meta-analysis included participants at both middle and old age.

\section{Limitations}

Due to the nature of the post-hoc observational design, our findings are open to residual confounding, and thus should be interpreted with caution. The results are also only based on one study, so are limited by low power. Another limitation of our study is missing details of LLT at baseline and in the post-trial period including reason for prescription, dose, duration and adherence to treatment. Compared to the 'no LLT' group, LLT participants had a substantially higher total cholesterol and were more likely to have previous BP lowering and antiplatelet use, to be diabetic and to have a family history of CVD suggesting that they were at higher underlying baseline risk. Covariate adjustment has limited ability to control for 'confounding by indication'. In the subgroup analysis by estimated CVD risk, age, sex and diabetes at baseline 
(Supplementary table 1), the magnitudes of the association between LLT and mortality were similar in stratified groups, except that the association between LLT and short-term all-cause mortality varied according to estimated CVD risk. The association between LLT and other short-term or long-term mortality was found to be independent of age, sex, diabetes and estimated CVD risk. Furthermore, confounding by indication would be expected to bias in favor of higher mortality in the LLT group. A final point is that the risk algorithm is for untreated populations in both groups, but underestimation should affect those in the LLT group to a greater extent as they were on lipid-lowering therapy.

In conclusion, our study supports the early use of LLT in those 65 years or over due to the association with long-term benefits on all-cause mortality, although the short-term benefits are likely to be evident only in the high-risk population. The findings suggest that the mortality benefit of LLT for the elderly may take longer to become evident. 


\section{Competing interests:}

CLBH is a Ph.D. candidate at Menzies Institute for Medical Research, she has received a Ph.D. scholarship from Merle Weaver Postgraduate Scholarship. JD is supported by National Health and Medical Research Council Screening and Test Evaluation Program Grant 633003. CR is supported by a National Health and Medical Research Council Senior Research Fellowship (1045862). MRN has served on an advisory board for AMGEN and Bayer. EKC, LW: no competing interests.

\section{Acknowledgement:}

ANBP2 was funded by a joint venture of the Commonwealth Government of Australia, the National Health and Medical Research Council, Merck Sharp \& Dohme, and academic institutions and the post-trial cohort by a Program Grant (546272) from the National Health and Medical Research Council. In the current study, the researchers gratefully acknowledge the RACGP Foundation and Therapeutic Guidelines Ltd for their support of this project.

On behalf of the Second Australian National Blood Pressure Management Committee: Lawrence J. Beilin (Department of Medicine, University of Western Australia, Perth, Australia); Garry L. Jennings (Baker IDI Heart and Diabetes Research Institute, Melbourne, Australia); Collin I. Johnston (Baker IDI Heart and Diabetes Research Institute, Melbourne, Australia); Graham J. Macdonald (Merck Sharp and Dohme, Sydney, Australia); John E. Marley (Faculty of Health, University of Newcastle, Newcastle, Australia); John J. McNeil (Department of Epidemiology and Preventive Medicine, Monash University, Melbourne, Australia); Trefor O. Morgan (Department of Physiology, University of Melbourne, Melbourne, Australia); Christopher M. Reid (Department of Epidemiology and Preventive Medicine, Monash University, Melbourne, Australia); Philip Ryan (Discipline of Public Health, University of Adelaide, Adelaide, Australia); Malcolm J. West (Department of Medicine, University of Queensland, Brisbane, Australia); Lindon M. H. Wing (School of Medicine, Flinders University, Adelaide, Australia).

Contributors: $M R N$ and $C R$ are responsible for the study conception and data archive. CLBH and EKC performed the analyses and CLBH drafted the manuscript. MB, CR, JD provided substantial support on statistical analyses. LMHW is the 
principle investigator in ANBP2. All authors contributed to the interpretation of data, critically revised the manuscript and approved the final version.

Ethics approval: ANBP2 was approved by the ethics committee of the Royal Australian College of General Practitioners and the post-trial cohort by the Monash University Standing Committee on Ethics in Research Involving Humans. The current cohort study was performed on non-identifiable dataset, thus an ethics approval was unnecessary. 


\section{References}

1. Wan He; Daniel Goodkind; and Paul Kowal. U.S. Census Bureau. International Population Reports, P95/16-1, An Aging World: 2015,. U.S. Government Publishing Office, Washington, DC,2016.

2. Prince MJ, Wu F, Guo Y, et al. The burden of disease in older people and implications for health policy and practice. The Lancet.385(9967):549-562.

3. Baigent C, Keech A, Kearney P, Blackwell L. Efficacy and safety of cholesterollowering treatment: prospective meta-analysis of data from 90056 participants in 14 randomised trials of statins. The Lancet. 2005;366(9493):1267.

4. Baigent C, Blackwell L, Emberson J, et al. Efficacy and safety of more intensive lowering of LDL cholesterol: a meta-analysis of data from 170,000 participants in 26 randomised trials. In: Elsevier; 2010.

5. Cholesterol Treatment Trialists Collaborators. The effects of lowering LDL cholesterol with statin therapy in people at low risk of vascular disease: metaanalysis of individual data from 27 randomised trials. The Lancet. 2012;380(9841):581-590.

6. Morgan TK, Williamson M, Pirotta M, Stewart K, Myers SP, Barnes J. A national census of medicines use: a 24-hour snapshot of Australians aged 50 years and older. Med J Aust. 2012;196(1):50-53.

7. Gu Q, Paulose-Ram R, Burt VL, Kit BK. Prescription cholesterol-lowering medication use in adults aged 40 and over: United States, 2003-2012. NCHS data brief, no 177. Hyattsville, MD: National Center for Health Statistics. 2014.

8. Afilalo J, Duque G, Steele R, Jukema JW, de Craen AJ, Eisenberg MJ. Statins for secondary prevention in elderly patients: a hierarchical bayesian metaanalysis. J Am Coll Cardiol. 2008;51(1):37-45.

9. Shepherd J, Blauw GJ, Murphy MB, et al. Pravastatin in elderly individuals at risk of vascular disease (PROSPER): a randomised controlled trial. The Lancet. 2002;360(9346):1623-1630.

10. Hunt D, Young P, Simes J, et al. Benefits of pravastatin on cardiovascular events and mortality in older patients with coronary heart disease are equal to or exceed those seen in younger patients: results from the LIPID trial. Ann Intern Med. $2001 ; 134(10): 931-940$. 
11. Miettinen TA, Pyörälä K, Olsson AG, et al. Cholesterol-lowering therapy in women and elderly patients with myocardial infarction or angina pectoris. Circulation. 1997;96(12):4211-4218.

12. Lewis SJ, Moye LA, Sacks FM, et al. Effect of pravastatin on cardiovascular events in older patients with myocardial infarction and cholesterol levels in the average range: results of the Cholesterol and Recurrent Events (CARE) trial. Ann Intern Med. 1998;129(9):681-689.

13. Colhoun HM, Betteridge DJ, Durrington PN, et al. Primary prevention of cardiovascular disease with atorvastatin in type 2 diabetes in the Collaborative Atorvastatin Diabetes Study (CARDS): multicentre randomised placebocontrolled trial. The Lancet. 2004;364(9435):685-696.

14. Downs JR, Clearfield M, Weis S, et al. Primary prevention of acute coronary events with lovastatin in men and women with average cholesterol levels: results of AFCAPS/TexCAPS. Jama. 1998;279(20):1615-1622.

15. Sever PS, Dahlöf B, Poulter NR, et al. Prevention of coronary and stroke events with atorvastatin in hypertensive patients who have average or lower-thanaverage cholesterol concentrations, in the Anglo-Scandinavian Cardiac Outcomes Trial-Lipid Lowering Arm (ASCOT-LLA): a multicentre randomised controlled trial. The Lancet. 2003;361(9364):1149-1158.

16. Ridker PM, Pradhan A, MacFadyen JG, Libby P, Glynn RJ. Cardiovascular benefits and diabetes risks of statin therapy in primary prevention: an analysis from the JUPITER trial. The Lancet. 2012;380(9841):565-571.

17. Redberg RF, Katz MH. Statins for primary prevention: The debate is intense, but the data are weak. JAMA. 2016;316(19):1979-1981.

18. Curfman G. Risks of statin therapy in older adults. JAMA Internal Medicine. 2017;177(7):966-966.

19. Gurwitz JH, Go AS, Fortmann SP. Statins for primary prevention in older adults: Uncertainty and the need for more evidence. JAMA. 2016;316(19):1971-1972.

20. Waters DD. Meta-Analyses of Statin Trials. In: Journal of the American College of Cardiology; 2013.

21. Savarese G, Gotto AM, Paolillo S, et al. Benefits of Statins in Elderly Subjects Without Established Cardiovascular Disease: A Meta-Analysis. J Am Coll Cardiol. 2013;62(22):2090-2099. 
22. Furberg CD, Wright JT, Davis BR, et al. Major outcomes in moderately hypercholesterolemic, hypertensive patients randomized to pravastatin vs usual care: the Antihypertensive and Lipid-Lowering Treatment to Prevent Heart Attack Trial (ALLHAT-LLT). J Am Med Assoc. 2002;288(23):2998-3007.

23. Lemaitre RN, Psaty BM, Heckbert SR, Kronmal RA, Newman AB, Burke GL. Therapy with hydroxymethylglutaryl coenzyme a reductase inhibitors (statins) and associated risk of incident cardiovascular events in older adults: Evidence from the cardiovascular health study. Archives of Internal Medicine. 2002;162(12):1395-1400.

24. Alpérovitch $A$, Kurth $T$, Bertrand $M$, et al. Primary prevention with lipid lowering drugs and long term risk of vascular events in older people: population based cohort study. BMJ. 2015;350.

25. Fried TR, Tinetti ME, Towle V, O'Leary JR, lannone L. Effects of benefits and harms on older persons; willingness to take medication for primary cardiovascular prevention. Archives of Internal Medicine. 2011;171(10):923-928.

26. Albarqouni L, Doust J, Glasziou P. Patient preferences for cardiovascular preventive medication: a systematic review. Heart. 2017:heartjnl-2017-311244.

27. Wing LMH, Reid CM, Ryan $P$, et al. A Comparison of Outcomes with Angiotensin-Converting-Enzyme Inhibitors and Diuretics for Hypertension in the Elderly. New England Journal of Medicine. 2003;348(7):583-592.

28. Nelson MR, Chowdhury EK, Doust J, Reid CM, Wing LM. Ten-year legacy effects of baseline blood pressure 'treatment naivety'in the Second Australian National Blood Pressure study. Journal of hypertension. 2015;33(11):2331-2337.

29. National Vascular Disease Prevention Alliance. Guidelines for the management of absolute cardiovascular disease risk. 2012.

30. Anderson K, Odell P, Wilson P, WB.K. Cardiovascular disease risk profiles. American Heart Journal. 1991;121:293-298.

31. Sever PS, Chang CL, Gupta AK, Whitehouse A, Poulter NR. The AngloScandinavian Cardiac Outcomes Trial: 11-year mortality follow-up of the lipidlowering arm in the UK. European Heart Journal. 2011;32(20):2525-2532.

32. Nielsen SF, Nordestgaard BG, Bojesen SE. Statin Use and Reduced CancerRelated Mortality. New England Journal of Medicine. 2012;367(19):1792-1802. 
33. Platz EA, Leitzmann MF, Visvanathan K, et al. Statin Drugs and Risk of Advanced Prostate Cancer. JNCl: Journal of the National Cancer Institute. 2006;98(24):1819-1825.

34. Cholesterol Treatment Trialists. Lack of effect of lowering LDL cholesterol on cancer: meta-analysis of individual data from 175,000 people in 27 randomised trials of statin therapy. PLoS One. 2012;7(1):e29849. 